\title{
Low-dose isoflavone aglycone alleviates psychological symptoms of menopause in Japanese women: a randomized, double-blind, placebo-controlled study
}

\author{
Asuka Hirose $^{1} \cdot$ Masakazu Terauchi $^{2} \cdot$ Mihoko Akiyoshi $^{1} \cdot$ Yoko Owa $^{1} \cdot$ \\ Kiyoko Kato $^{1}$ - Toshiro Kubota ${ }^{1}$
}

Received: 14 November 2014/Accepted: 11 August 2015/Published online: 21 August 2015

(C) The Author(s) 2015. This article is published with open access at Springerlink.com

\begin{abstract}
Purpose Many studies have demonstrated the effectiveness of isoflavones on menopausal symptoms; however, these mostly used high dosages. Because high-dose isoflavone may result in endometrial hyperplasia, we investigated whether low-dose isoflavone aglycone alleviates menopausal symptoms similarly to high dosages.

Methods We conducted a randomized, double-blind, placebo-controlled study in 90 healthy women aged 40-60 years who had at least one menopausal symptom on the Menopausal Symptom Scale (MSS). The participants were randomized to receive active tablets containing ultralow-dose $(12.5 \mathrm{mg} /$ day; $n=30)$ or low-dose $(25 \mathrm{mg} /$ day; $n=30)$ isoflavone aglycone, or placebo $(n=30)$ tablets, for 8 weeks. Their menopausal symptoms were evaluated using MSS, Hospital Anxiety and Depression Scale (HADS), and Athens Insomnia Scale (AIS) before, and 4 and 8 weeks after treatment.

Results Eighty-seven women (97\%) completed the 8 -week treatment. In the low-dose group, significant improvement was observed from baseline, in the following parameters: (1) HADS-depression subscale score, (2) AIS score, (3) MSS-somatic symptom score after 4 and 8 weeks of treatment, and (4) MSS-vasomotor symptom score after 8 weeks of treatment. The changes in scores on HADS-
\end{abstract}

Masakazu Terauchi

teragyne@tmd.ac.jp

1 Department of Obstetrics and Gynecology, Tokyo Medical and Dental University, Yushima 1-5-45, Bunkyo, Tokyo 113-8510, Japan

2 Department of Women's Health, Tokyo Medical and Dental University, Yushima 1-5-45, Bunkyo, Tokyo 113-8510, Japan depression subscale and AIS from baseline to 8 weeks were significantly higher in the low-dose group than in the placebo group.

Conclusions Low-dose ( $25 \mathrm{mg} /$ day) isoflavone aglycone significantly alleviated symptoms of depression and insomnia in Japanese middle-aged women.

Clinical Trial Registration UMIN-CTR UMIN000011876.

Keywords Flavonoids - Depression - Insomnia - Mood . Sleep

\section{Introduction}

The advent of an aging society is raising various healthcare issues in developed countries. Health promotion in women at midlife has gained paramount importance. Menopausal symptoms, such as hot flushes, night sweats, vaginal dryness, anxiety, depression, and insomnia, are among the major factors compromising the quality of life of middle-aged women. Although menopausal hormone therapy (MHT) effectively alleviates vasomotor and other menopausal symptoms, some women are unwilling or have contraindications to receive MHT owing to the onset of adverse effects, such as venous thromboembolism, stroke, and breast cancer. These women often use dietary supplements, including soy isoflavones, for the relief of menopausal symptoms. In this context, previously, grape seed proanthocyanidin extract has shown to alleviate physical and psychological symptoms of menopause, while increasing muscle mass and reducing blood pressure in middle-aged women [1].

Isoflavones are plant-derived flavonoids that are particularly abundant in leguminous crops and mimic the actions of estrogen by binding to estrogen receptors (ERs) $\alpha$ and $\beta$, 
and thus isoflavones are referred to as phytoestrogens. Isoflavones are contained in soybean or soy foods in two distinct chemical forms, glucosides and aglycones, and the latter are absorbed faster and in greater amounts in the human intestine than glucosides [2].

A number of clinical studies have suggested that soy or soy isoflavone may alleviate menopausal symptoms, especially vasomotor symptoms [3-11], supposedly through its estrogen receptor agonist $[3,5,12-16]$ and antioxidant activities [17]. However, some randomized controlled trials failed to demonstrate their effectiveness [18-22]. The discrepancy may be because of the differences in participant age, duration since menopause, symptom severity, symptom assessment system, dose of isoflavones, proportion of aglycones contained, bioavailability of aglycones and glucosides, and baseline dietary intake of isoflavones.

In 2004, a randomized, double-blind, placebo-controlled trial including 319 postmenopausal Italian women revealed that 5 -year treatment with $150 \mathrm{mg} /$ day of soy isoflavones significantly increased the occurrence of endometrial hyperplasia (3.4 vs. $0 \%, P<0.05$ ) [16]. Alarmed by this report, the Japanese Food Safety Commission propounded, in 2006, that the safe upper limit of daily intake of isoflavone aglycones should be restricted to $70-75 \mathrm{mg}$, thus limiting the amount that can be taken from dietary supplements to $30 \mathrm{mg}$ or less [23]. Considering that most of the aforementioned studies that showed the effectiveness of isoflavone aglycones on menopausal symptoms were conducted using higher doses than the recommended levels, we examined whether lower doses of soy isoflavone aglycone improve menopausal symptoms or not.

\section{Materials and methods}

A randomized, double-blind, placebo-controlled study was conducted from June 2013 to December 2013 at the Menopause Clinic of the Tokyo Medical and Dental University. The study protocol was reviewed and approved by the Tokyo Medical and Dental University Review Board, and a written informed consent was obtained from all participants. The study was conducted in accordance with the Declaration of Helsinki.

Japanese women aged 40-60 years who had at least one menopausal symptom on the Menopausal Symptom Scale (MSS) were eligible for the study. Those who were already receiving MHT were excluded. The participants were classified as follows: premenopausal (regular menstrual cycles in the past 3 months), perimenopausal (a menstrual period within the past 12 months, but a missed period or irregular cycles in the past 3 months), postmenopausal (no menstrual period in the past 12 months), or had surgically induced menopause (hysterectomy) [24].

The participants were randomized into one of three groups to receive active tablets containing ultralow-dose $(12.5 \mathrm{mg} / \mathrm{day} ; n=30)$ or low-dose $(25 \mathrm{mg} / \mathrm{day} ; n=30)$ isoflavone aglycone, or placebo $(n=30)$. They were instructed to take the supplement for an 8-week period. The ultralow-dose and low-dose isoflavone aglycone, and placebo tablets, indistinguishable in shape, weight, and color, were manufactured and packaged by Kikkoman Corporation (Noda, Japan). Isoflavones contained in the tablet are all in aglycone forms: genistein, $51.8 \%$; daidzein, $43.3 \%$; and glycitein, $4.9 \%$. The women were instructed to take one tablet per day at any time of the day. Medication adherence was evaluated by collecting the packages of the supplements.

The participants sequentially numbered received supplement packages with the corresponding number assigned by the manufacturer. The content of each package, namely ultralow-dose or low-dose isoflavone aglycone, or placebo, was not revealed until the end of the study period, so that the allocation was concealed from both the participants and the investigators.

The menopausal symptoms of the participants were evaluated using the MSS, Hospital Anxiety and Depression Scale (HADS) and Athens Insomnia Scale (AIS) before and after 4 and 8 weeks of treatment.

The MSS has been used and validated in previous studies, in which patients rate the severity of ten menopausal symptoms at every visit [25]. The MSS evaluates vasomotor symptoms (hot flush, perspiration, and chilliness); somatic symptoms (irregular heartbeat, headache/ dizziness, tiredness, and aching joints/muscles); and psychological symptoms (insomnia, irritability, and depressed mood) using a four-point Likert scale depending on how often each symptom affects their daily life: none (never, 0 point); mild (rarely, 1 point); moderate (sometimes, 2 points); or severe (very often, 3 points). Vasomotor and somatic symptom scores are calculated as the total score of three and four aforementioned symptoms, respectively.

Developed by Zigmond and Snaith as a questionnaire [26], HADS is a reliable instrument for screening clinically significant anxiety and depression in women visiting a general medical clinic, which has been translated into Japanese by Kitamura et al. [27]. The AIS was developed as a brief and easy-to-administer self-assessment questionnaire for determining the severity of insomnia defined according to the International Classification of Disease Tenth Revision. The internal consistency and test-retest reliability of AIS have been confirmed previously [28]. The current study was conducted in a manner similar to a previous one using grape seed proanthocyanidin extract, in 
which detailed information about HADS and AIS questionnaires is provided [1].

The body composition of the participants, including height, weight, body mass index, fat mass, and muscle mass, was assessed using a body composition analyzer (MC190-EM; Tanita, Tokyo, Japan). Their cardiovascular parameters, including systolic blood pressure, diastolic blood pressure, and heart rate, were also measured using a vascular screening system (VS-1000; Fukuda Denshi Co., Tokyo, Japan).

All statistical analyses were performed with GraphPad Prism version 5.02 (GraphPad Software Incorporated, CA, USA) using one-way analysis of variance, $\chi^{2}$ test, Kruskal-Wallis test, Wilcoxon signed-rank test, and Mann-Whitney test. $P<0.05$ was considered to be statistically significant.

\section{Results}

A total of 90 middle-aged women were enrolled in the study and randomized to the ultralow-dose $(n=30)$, lowdose $(n=30)$, or placebo groups $(n=30)$; of these, 87 (97\%) completed the 8-week treatment period (Fig. 1). The baseline characteristics of the participants who completed the 8-week treatment are shown in Table 1. Their mean age was $48-51$ years; 38-66\% of the women were premenopausal, while 10-17\% were perimenopausal, $21-41 \%$ were postmenopausal, and 3-10\% had surgically induced menopause. No statistically significant differences were observed in the baseline characteristics among the study groups, except for the mean MSS-vasomotor symptom score: at baseline, the score in the ultralow-dose group was higher than in the other groups.

We evaluated the severity of menopausal symptoms after 4 and 8 weeks of treatment in each study group. In psychological symptoms, the mean HADS-depression subscale score improved in the low-dose group after 4 and

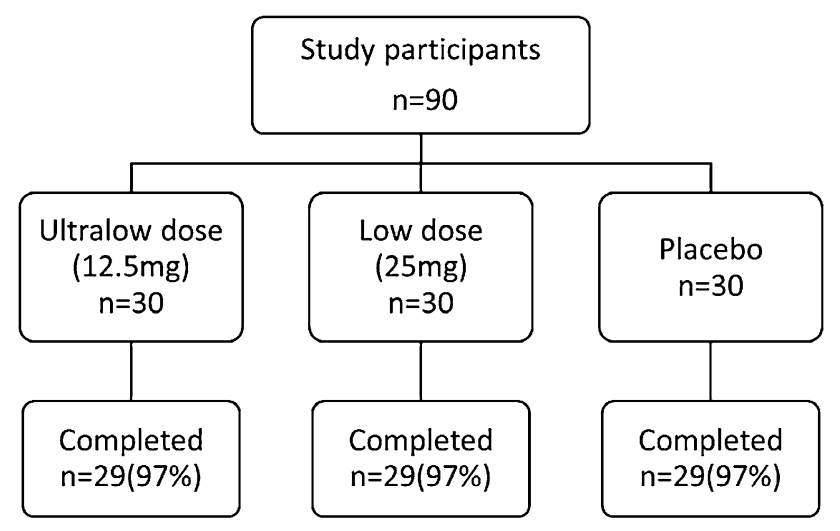

Fig. 1 Participant disposition
8 weeks of treatment $(4.1 \pm 0.4$ vs. $3.5 \pm 0.5$ and $3.0 \pm 0.5$, mean \pm SEM, $\mathrm{P}=0.032$ and 0.003 , vs. baseline) (Fig. 2a), but not in the ultralow-dose and placebo groups, whereas the mean HADS-anxiety subscale score did not change significantly in any of the groups (Fig. 2b). Similarly, the mean AIS score improved only in the lowdose group after 4 and 8 weeks $(5.0 \pm 0.6$ vs. $3.2 \pm 0.4$ and $3.2 \pm 0.5, P=0.0006$ and 0.002) (Fig. 2c). As for vasomotor and somatic symptoms, the mean MSS-vasomotor symptom score significantly improved in the lowdose group after 8 weeks $(3.1 \pm 0.4$ vs. $2.3 \pm 0.4$, $P=0.010$ ) (Fig. 2d), and the mean MSS-somatic symptom score significantly improved only in the low-dose group after 4 and 8 weeks $(5.0 \pm 0.5$ vs. $3.9 \pm 0.5$ and $3.8 \pm 0.5, P=0.023$ and 0.002 ) (Fig. 2e). There was no significant improvement in the ultralow-dose and placebo groups.

The changes in scores on HADS-depression subscale and AIS from baseline to 8 weeks were significantly higher in the low-dose group than in the placebo group: HADSdepression subscale score $(-1.15 \pm 0.34 \quad$ vs. $-0.07 \pm 0.28$, mean \pm SEM, $P=0.033)$; AIS score $(-1.82 \pm 0.62$ vs. $-0.10 \pm 0.38, P=0.014)$.

Neither the body composition parameters nor the cardiovascular parameters changed significantly in any of the groups (data not shown).

During the whole study period, no treatment-emergent adverse event was reported from participants, even though laboratory tests or transvaginal ultrasound were not routinely performed.

\section{Discussion}

We conducted a randomized, double-blind, placebo-controlled study to examine the effects of ultralow and lowdose isoflavone aglycone derived from soybeans on the symptoms of middle-aged women. As a result, the lowdose ( $25 \mathrm{mg} /$ day) isoflavone aglycone significantly alleviated symptoms of depression and insomnia in Japanese middle-aged women.

Leguminous crops, utilized as foods from ancient times, especially in Asian countries, have been generally well tolerated without any remarkable health hazards. However, the alarm raised by the Italian study that showed an increase in endometrial hyperplasia after 5-year intake of $150 \mathrm{mg} /$ day of isoflavones [16] prompted the Japanese Food Safety Commission to propound the safe upper limit of daily intake of isoflavone aglycones to $70-75 \mathrm{mg}$ in 2006. This limitation reflected in the amount that can be consumed in dietary supplements, which was reduced to $30 \mathrm{mg}$ or less [23]. Therefore, we conducted this study with ultralow-dose (12.5 mg/day) or low-dose (25 mg/day) 
Table 1 Baseline characteristics

\begin{tabular}{|c|c|c|c|c|}
\hline & Placebo $(n=29)$ & Ultralow dose $(n=29)$ & Low dose $(n=29)$ & $P$ \\
\hline \multicolumn{5}{|l|}{ Age and menopausal status } \\
\hline Age, mean (SD), years & $48.0(5.7)$ & $50.5(4.7)$ & $47.6(4.9)$ & $0.080^{\mathrm{a}}$ \\
\hline $\begin{array}{l}\text { Premenopausal/ } \\
\text { perimenopausal/ } \\
\text { postmenopausal/had surgically } \\
\text { induced menopause, number }(\%)\end{array}$ & $15 / 5 / 6 / 3,(51.7 / 17.2 / 20.7 / 10.3)$ & 11/5/12/1, (37.9/17.2/41.4/3.4) & $19 / 3 / 6 / 1,(65.5 / 10.3 / 20.7 / 3.4)$ & $0.290^{\mathrm{b}}$ \\
\hline \multicolumn{5}{|l|}{ Physical symptom score, mean (SD) } \\
\hline MSS-vasomotor symptom score & $3.0(2.2)$ & $4.4(2.1)$ & $3.1(2.2)$ & $0.018^{\mathrm{c}}$ \\
\hline MSS-somatic symptom score & $4.0(2.5)$ & $4.7(2.3)$ & $5.0(2.8)$ & $0.446^{\mathrm{c}}$ \\
\hline \multicolumn{5}{|c|}{ Psychological symptom score, mean (SD) } \\
\hline HADS-anxiety subscale score & $5.3(2.5)$ & $5.1(2.3)$ & $5.5(3.3)$ & $0.828^{\mathrm{c}}$ \\
\hline HADS-depression subscale score & $4.4(2.3)$ & $4.0(2.1)$ & $4.1(2.1)$ & $0.773^{\mathrm{c}}$ \\
\hline Athens Insomnia Scale score & $4.1(3.0)$ & $3.9(2.6)$ & $5.0(3.3)$ & $0.337^{\mathrm{c}}$ \\
\hline \multicolumn{5}{|l|}{ Body composition, mean (SD) } \\
\hline Height $(\mathrm{cm})$ & $158.1(4.8)$ & $157.4(3.8)$ & $158.6(5.0)$ & $0.596^{\mathrm{a}}$ \\
\hline Weight (kg) & $54.5(7.7)$ & $56.3(9.0)$ & $54.2(7.7)$ & $0.579^{\mathrm{a}}$ \\
\hline Body mass index $\left(\mathrm{kg} / \mathrm{m}^{2}\right)$ & $21.8(2.7)$ & $22.7(3.2)$ & $21.6(3.2)$ & $0.650^{\mathrm{a}}$ \\
\hline Fat mass $(\mathrm{kg})$ & $14.9(5.2)$ & $17.0(6.3)$ & $14.7(5.7)$ & $0.279^{\mathrm{a}}$ \\
\hline Muscle mass $(\mathrm{kg})$ & $37.3(2.8)$ & $37.1(3.1)$ & $37.2(2.7)$ & $0.972^{\mathrm{a}}$ \\
\hline \multicolumn{5}{|l|}{ Cardiovascular parameters, mean (SD) } \\
\hline Systolic blood pressure (mmHg) & $117.3(13.8)$ & $117.2(15.7)$ & $121.0(20.7)$ & $0.651^{\mathrm{a}}$ \\
\hline Diastolic blood pressure (mmHg) & $63.7(12.0)$ & $67.8(12.9)$ & $67.6(13.1)$ & $0.406^{\mathrm{a}}$ \\
\hline Heart rate $\left(\mathrm{min}^{-1}\right)$ & $69.7(9.0)$ & $73.3(10.2)$ & $69.0(8.9)$ & $0.188^{\mathrm{a}}$ \\
\hline
\end{tabular}

isoflavone aglycone to examine whether lower doses of soy isoflavone aglycone could improve menopausal symptoms or not.

The most remarkable results in the present study were the significant improvements in psychological symptoms such as depression and insomnia with the use of the lowdose isoflavone. Compared with vasomotor symptoms, there are fewer randomized, double-blind, placebo-controlled studies that demonstrated the effects of isoflavones on psychological symptoms: two studies showed significant improvement in depression [29, 30] and one in insomnia [31]. Atteritano et al. showed improvements in depression with $54 \mathrm{mg}$ isoflavone in a 2-year study, though the genistein and placebo tablets contained calcium carbonate and vitamin D as well [29]. Lipovac et al. revealed that $80 \mathrm{mg}$ red clover-derived isoflavones administered for a 90-day period reduced depressive and anxiety symptoms [30], whereas Hachul et al. showed that 4-month treatment with $80 \mathrm{mg}$ isoflavone was effective for insomnia [31]. However, all of these three trials used higher dosage and longer treatment periods than ours.
Although the mechanisms by which isoflavones improve depression and insomnia have not been fully explained, experiments in ovariectomized rats revealed that phytoestrogen genistein had antidepressant-like and anxiolyticlike effects probably through their estrogenic activities [32, 33]. Recent hypotheses suggest that estrogens affect the hippocampus, a limbic region implicated in mood disorders [34], through ER $\beta$ [35]. Because isoflavones have higher affinity to ER $\beta$ than to ER $\alpha$ [36], they may well be effective for psychological symptoms of menopause.

Psychological symptoms could derive from vasomotor symptoms, through so-called domino effect [37], with nightly vasomotor symptoms leading to insomnia, and then to depression, although some studies showed that depression and insomnia were independent of vasomotor symptoms [38, 39]. In the present study, we found that the changes in psychological symptoms were significantly higher in the low-dose group than in the placebo group, but not in vasomotor symptoms. Therefore, the domino effect would not likely be the underlying mechanism for the improvement of psychological symptoms. The effects of 
Fig. 2 The changes from baseline in: a Hospital Anxiety and Depression Scale (HADS)depression subscale score; b HADS-anxiety subscale score; c Athens Insomnia Scale (AIS) score; d Menopausal Symptom Scale (MSS)-vasomotor symptom score; and e MSSsomatic symptom score (mean and standard error, $* P<0.05$, $* * P<0.01, * * * P<0.001$ versus baseline, Wilcoxon signed-rank test. ${ }^{\#} P<0.05$, change from baseline versus placebo, Mann-Whitney test) a HADS-depression subscale score

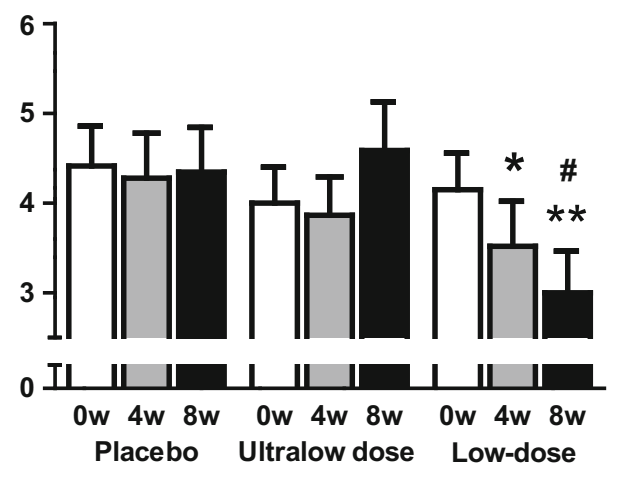

b HADS-anxiety subscale score

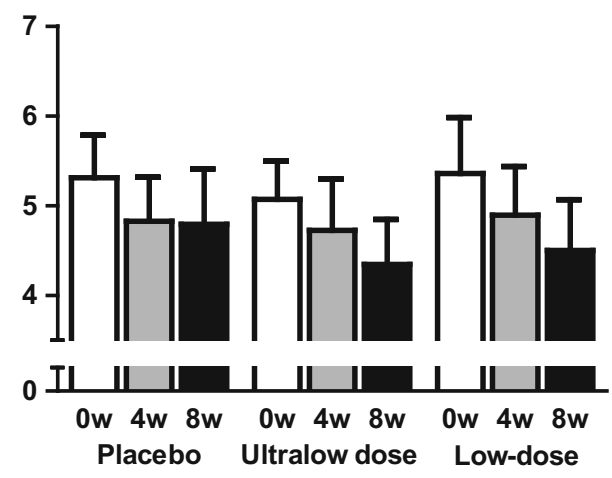

AIS score

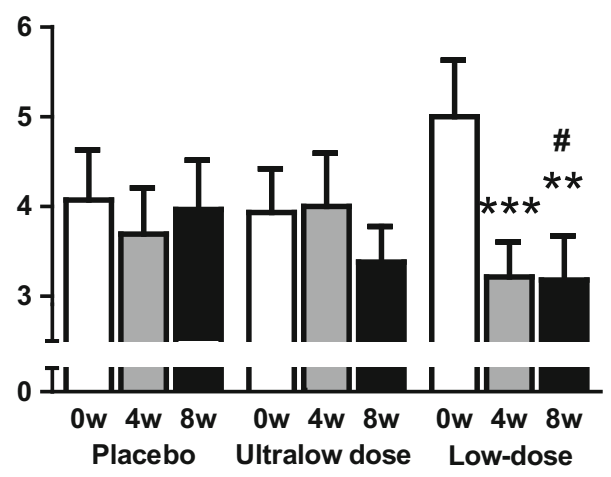

d MSS-vasomotor symptom score

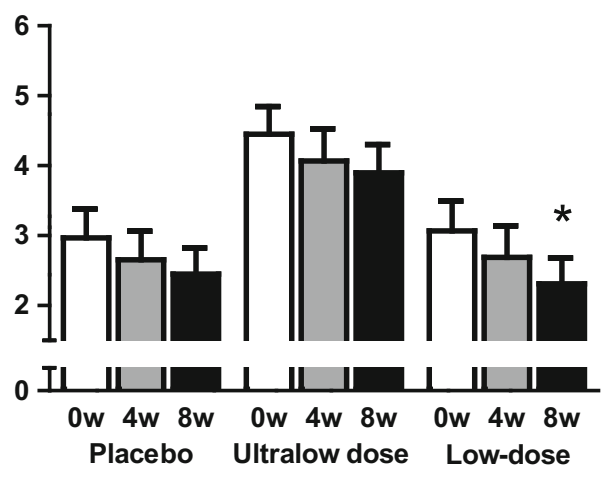

e MSS-somatic symptom score

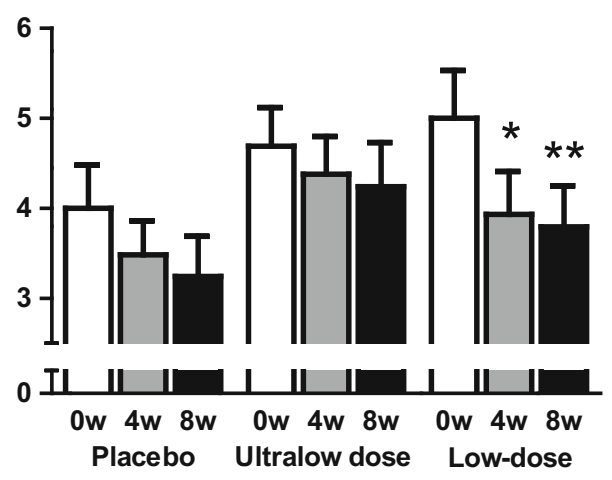

low-dose isoflavone on depression and insomnia were not significantly different by menopausal status either.

The reason why isoflavone at the low dose of $25 \mathrm{mg} /$ day effectively alleviated menopausal symptoms in the current study may be because the soy isoflavones we administered were completely presented in the aglycone form, which is absorbed faster and in greater amounts than the glucoside form [2]. Six studies that administered isoflavones only in aglycone forms $[3,5,6,8,10,11]$ showed significant improvement in vasomotor symptoms. Alternatively, the soy isoflavone we used may have been effective because it was rich in genistein, which has higher estrogenic activity than daidzein and other phytoestrogens [40].
The present study has some limitations: (1) the number of participants was relatively small; (2) the study period was as short as 8 weeks; (3) the differences in symptom scores from baseline to the end of follow-up were relatively small, even though some of them reached statistical significance; and (4) the effects of isoflavones on endometrial thickness and histology were not evaluated. A study with a larger sample and longer duration, including women with more severe menopausal symptoms, could further clarify the effects of low-dose isoflavone aglycone on menopausal symptoms.

In conclusion, the present study revealed that low-dose $(25 \mathrm{mg} /$ day $)$ isoflavone aglycone significantly alleviated 
symptoms of depression and insomnia in Japanese middleaged women.

Acknowledgments This research was supported by Kikkoman Corporation.

\section{Compliance with ethical standards}

Conflict of interest MT. received a research grant from Kikkoman Corporation.

Open Access This article is distributed under the terms of the Creative Commons Attribution 4.0 International License (http://creative commons.org/licenses/by/4.0/), which permits unrestricted use, distribution, and reproduction in any medium, provided you give appropriate credit to the original author(s) and the source, provide a link to the Creative Commons license, and indicate if changes were made.

\section{References}

1. Terauchi M, Horiguchi N, Kajiyama A, Akiyoshi M, Owa Y, Kato K, Kubota T (2014) Effects of grape seed proanthocyanidin extract on menopausal symptoms, body composition, and cardiovascular parameters in middle-aged women: a randomized, double-blind, placebo-controlled pilot study. Menopause 21:990-996

2. Izumi T, Piskula MK, Osawa S, Obata A, Tobe K, Saito M, Kataoka S, Kubota Y, Kikuchi M (2000) Soy isoflavone aglycones are absorbed faster and in higher amounts than their glucosides in humans. J Nutr 130:1695-1699

3. Albertazzi P, Pansini F, Bonaccorsi G, Zanotti L, Forini E, De Aloysio D (1998) The effect of dietary soy supplementation on hot flushes. Obstet Gynecol 91:6-11

4. Upmalis DH, Lobo R, Bradley L, Warren M, Cone FL, Lamia CA (2000) Vasomotor symptom relief by soy isoflavone extract tablets in postmenopausal women: a multicenter, double-blind, randomized, placebo-controlled study. Menopause 7:236-242

5. Han KK, Soares JM, Haidar MA, de Lima GR, Baracat EC (2002) Benefits of soy isoflavone therapeutic regimen on menopausal symptoms. Obstet Gynecol 99:389-394

6. Crisafulli A, Marini H, Bitto A, Altavilla D, Squadrito G, Romeo A, Adamo EB, Marini R, D'Anna R, Corrado F, Bartolone S, Frisina N, Squadrito F (2004) Effects of genistein on hot flushes in early postmenopausal women: a randomized, double-blind EPT- and placebo-controlled study. Menopause 11:400-404

7. Cheng G, Wilczek B, Warner M, Gustafsson JA, Landgren BM (2007) Isoflavone treatment for acute menopausal symptoms. Menopause 14:468-473

8. D'Anna R, Cannata ML, Atteritano M, Cancellieri F, Corrado F, Baviera G, Triolo O, Antico F, Gaudio A, Frisina N, Bitto A, Polito F, Minutoli L, Altavilla D, Marini H, Squadrito F (2007) Effects of the phytoestrogen genistein on hot flushes, endometrium, and vaginal epithelium in postmenopausal women: a 1-year randomized, double-blind, placebo-controlled study. Menopause 14:648-655

9. Nahas EA, Nahas-Neto J, Orsatti FL, Carvalho EP, Oliveira ML, Dias R (2007) Efficacy and safety of a soy isoflavone extract in postmenopausal women: a randomized, double-blind, and placebo-controlled study. Maturitas 58:249-258

10. Khaodhiar L, Ricciotti HA, Li L, Pan W, Schickel M, Zhou J, Blackburn GL (2008) Daidzein-rich isoflavone aglycones are potentially effective in reducing hot flashes in menopausal women. Menopause 15:125-132
11. Evans M, Elliott JG, Sharma P, Berman R, Guthrie N (2011) The effect of synthetic genistein on menopause symptom management in healthy postmenopausal women: a multi-center, randomized, placebo-controlled study. Maturitas 68:189-196

12. Jacobs A, Wegewitz U, Sommerfeld C, Grossklaus R, Lampen A (2009) Efficacy of isoflavones in relieving vasomotor menopausal symptoms-a systematic review. Mol Nutr Food Res 53:1084-1097

13. Nelson HD, Vesco KK, Haney E, Fu R, Nedrow A, Miller J, Nicolaidis C, Walker M, Humphrey L (2006) Nonhormonal therapies for menopausal hot flashes: systematic review and meta-analysis. JAMA 295:2057-2071

14. Tempfer CB, Bentz EK, Leodolter S, Tscherne G, Reuss F, Cross HS, Huber JC (2007) Phytoestrogens in clinical practice: a review of the literature. Fertil Steril 87:1243-1249

15. Eden JA (2012) Phytoestrogens for menopausal symptoms: a review. Maturitas 72:157-159

16. Unfer V, Casini ML, Costabile L, Mignosa M, Gerli S, Di Renzo GC (2004) Endometrial effects of long-term treatment with phytoestrogens: a randomized, double-blind, placebo-controlled study. Fertil Steril 82:145-148 (quiz 265)

17. Wei H, Bowen R, Cai Q, Barnes S, Wang Y (1995) Antioxidant and antipromotional effects of the soybean isoflavone genistein. Proc Soc Exp Biol Med 208:124-130

18. St Germain A, Peterson CT, Robinson JG, Alekel DL (2001) Isoflavone-rich or isoflavone-poor soy protein does not reduce menopausal symptoms during 24 weeks of treatment. Menopause $8: 17-26$

19. Knight DC, Howes JB, Eden JA, Howes LG (2001) Effects on menopausal symptoms and acceptability of isoflavone-containing soy powder dietary supplementation. Climacteric 4:13-18

20. Burke GL, Legault C, Anthony M, Bland DR, Morgan TM, Naughton MJ, Leggett K, Washburn SA, Vitolins MZ (2003) Soy protein and isoflavone effects on vasomotor symptoms in periand postmenopausal women: the Soy Estrogen Alternative Study. Menopause 10:147-153

21. Duffy R, Wiseman H, File SE (2003) Improved cognitive function in postmenopausal women after 12 weeks of consumption of a soya extract containing isoflavones. Pharmacol Biochem Behav 75:721-729

22. Campagnoli C, Abbà C, Ambroggio S, Peris C, Perona M, Sanseverino P (2005) Polyunsaturated fatty acids (PUFAs) might reduce hot flushes: an indication from two controlled trials on soy isoflavones alone and with a PUFA supplement. Maturitas 51:127-134

23. Food Safety Commission of Japan (2006) Fundamental Concepts in the Safety Assessment of Foods Containing Soy Isoflavones for the purpose of Specified Health Use, in Japanese. http://www.fsc. go.jp/sonota/daizu_isoflavone.html. Accessed 6 July 2015

24. Kravitz HM, Ganz PA, Bromberger J, Powell LH, Sutton-Tyrrell K, Meyer PM (2003) Sleep difficulty in women at midlife: a community survey of sleep and the menopausal transition. Menopause 10:19-28

25. Terauchi M, Obayashi S, Akiyoshi M, Kato K, Matsushima E, Kubota T (2010) Insomnia in Japanese peri- and postmenopausal women. Climacteric 13:479-486

26. Zigmond AS, Snaith RP (1983) The hospital anxiety and depression scale. Acta Psychiatr Scand 67:361-370

27. Zigmond AS, Snaith RP, Kitamura T (1993) The hospital anxiety and depression scale (in Japanese). Seisinka-Sindangaku 4:371-372

28. Soldatos CR, Dikeos DG, Paparrigopoulos TJ (2000) Athens Insomnia Scale: validation of an instrument based on ICD-10 criteria. J Psychosom Res 48:555-560

29. Atteritano M, Mazzaferro S, Bitto A, Cannata ML, D'Anna R, Squadrito F, Macrì I, Frisina A, Frisina N, Bagnato G (2014) 
Genistein effects on quality of life and depression symptoms in osteopenic postmenopausal women: a 2-year randomized, double-blind, controlled study. Osteoporos Int 25:1123-1129

30. Lipovac M, Chedraui P, Gruenhut C, Gocan A, Stammler M, Imhof M (2010) Improvement of postmenopausal depressive and anxiety symptoms after treatment with isoflavones derived from red clover extracts. Maturitas 65:258-261

31. Hachul H, Brandão LC, D'Almeida V, Bittencourt LR, Baracat EC, Tufik S (2011) Isoflavones decrease insomnia in postmenopause. Menopause 18:178-184

32. Rodríguez-Landa JF, Hernández-Figueroa JD, BeC HernándezCalderón, Saavedra M (2009) Anxiolytic-like effect of phytoestrogen genistein in rats with long-term absence of ovarian hormones in the black and white model. Prog Neuropsychopharmacol Biol Psychiatry 33:367-372

33. Kageyama A, Sakakibara H, Zhou W, Yoshioka M, Ohsumi M, Shimoi K, Yokogoshi H (2010) Genistein regulated serotonergic activity in the hippocampus of ovariectomized rats under forced swimming stress. Biosci Biotechnol Biochem 74:2005-2010

34. Vaidya VA, Fernandes K, Jha S (2007) Regulation of adult hippocampal neurogenesis: relevance to depression. Expert Rev Neurother 7:853-864

35. Liu F, Day M, Muñiz LC, Bitran D, Arias R, Revilla-Sanchez R, Grauer S, Zhang G, Kelley C, Pulito V, Sung A, Mervis RF,
Navarra R, Hirst WD, Reinhart PH, Marquis KL, Moss SJ, Pangalos MN, Brandon NJ (2008) Activation of estrogen receptor-beta regulates hippocampal synaptic plasticity and improves memory. Nat Neurosci 11:334-343

36. Dornstauder E, Jisa E, Unterrieder I, Krenn L, Kubelka W, Jungbauer A (2001) Estrogenic activity of two standardized red clover extracts (Menoflavon) intended for large scale use in hormone replacement therapy. J Steroid Biochem Mol Biol 78:67-75

37. Campbell S, Whitehead M (1977) Oestrogen therapy and the menopausal syndrome. Clin Obstet Gynaecol 4:31-47

38. Freedman RR, Roehrs TA (2004) Lack of sleep disturbance from menopausal hot flashes. Fertil Steril 82:138-144

39. Schmidt PJ, Nieman L, Danaceau MA, Tobin MB, Roca CA, Murphy JH, Rubinow DR (2000) Estrogen replacement in perimenopause-related depression: a preliminary report. Am J Obstet Gynecol 183:414-420

40. Kuiper GG, Lemmen JG, Carlsson B, Corton JC, Safe SH, van der Saag PT, van der Burg B, Gustafsson JA (1998) Interaction of estrogenic chemicals and phytoestrogens with estrogen receptor beta. Endocrinology 139:4252-4263 